\title{
Elemental Composition of Suspended Particulate Matter Collected at Two Different Heights above the Ground in A Sub-Urban Site in Kenya Gitari W. M ${ }^{1}$, Kinyua A. M. ${ }^{2}$, Kamau G. ${ }^{3}$ and C. K. Gatebe C. K ${ }^{4}$
}

\begin{abstract}
Suspended particulate matter samples were collected in a sub-urban area in Nairobi over a 12 month period at two different heights above ground using a "Gent" SFU sampler. A total of 126 sets of duplicate fine and coarse particulate matter samples were collected. The samples were analysed by energy dispersive $x$-ray fluorescence (EDXRF) and atomic absorption spectroscopy (AAS) for up to 10 elements. It was found that $66 \%$ of the samples collected at two metres and $50 \%$ of the samples collected at four metres height exceeded the WHO 24 guideline of $70 \mu \mathrm{g} \mathrm{m} \mathrm{m}^{-3}$. Reduction in concentration of between 30 to $74 \% \mathrm{for} \mathrm{Ca,} \mathrm{Ti}, \mathrm{Zr}$ and Fe were observed both in coarse and fine particulate matter fractions at the higher height. The elements $\mathrm{Cu}, \mathrm{Zn}, \mathrm{Pb}$ and $\mathrm{Br}$ represented 0.5 to $1.1 \%$ of the total coarse particulate matter at both heights. Higher proportions of 1.5 to $3.5 \%$ were observed at both heights in the fine particulate matter fraction. High enrichment factors were observed for $\mathrm{Cu}$ (10.8 - 228.3), $\mathrm{Zn} \mathrm{(12.4} \mathrm{-} \mathrm{124.6),} \mathrm{Pb}$ (59.4 - 1967) and $\mathrm{Br}$ (152.5 - 3038.7) at both heights suggesting anthropogenic activities such as industrial, urban refuse burning, residential and vehicular emissions could be the major contributors. $\mathrm{Pb}$ and $\mathrm{Br}$ were mainly from the vehicular emissions as indicated by the strong correlations ( $r>0.593$ ) and the $\mathrm{Br} / \mathrm{Pb}$ ratios (0.307 to 0.339).
\end{abstract}

Keywords: Sub-urban, EDXRF, AAS, Enrichment factors, Heavy metals, particulate matter.

\section{Introduction}

Clevated levels of heavy metals vegetation and air in the vicinity of certain industries like smelters, mines, battery manufacturing and near busy roads and within urban area in general. The measured levels of heavy metals serve as an index of the extent of pollution (Nguyen et al; 1997; Khandekar et al; 1980). Although some metals such as Mn, Fe, $\mathrm{Cu}$ and $\mathrm{Zn}$ are essential micronutrients are toxic if exposure levels are sufficiently high (Prasad, 1988).

Numerous studies (Mahadevan et al; 1989; Karue et al; 1992; Noll et al; 1990) have demonstrated that metal contaminated environments are reflected by metal concentrations in suspended particulate matter. In Kenya several studies on elemental characterisation of suspended particulate matter have been done in the city of Nairobi (Karue et al; 1992; Gatebe et al; 1994) but non has ever concentrated on determination of in a slum set-up. This study was designed with an aim of assessing the load of heavy metals in the air of a densely populated slum area. The dense population, high density housing, the bare playgrounds, unpaved roads/footpaths all were suspected to contribute to the high levels of suspended particulate matter. High temperature processes such as the metal welding works could greatly contribute to contamination of surface dust by heavy metals as fine particle fallout. People living in these areas could be at high risk of exposure to these metals considering some of the activities popularly known as "juakali business" such as cooking and selling of cooked food, vegetables and other wares that are carried out besides the roads/footpaths. Moreover the children playing on these paths could be at higher risk from inhaling the contaminated dust.

Samples were collected at two different heights above the ground as an attempt to determine various sources of metals from within and outside the area and also quantify the effect of resuspended soil/road dust on the levels of suspended particulate matter $\left(\mathrm{PM}_{10}\right)$ at the lower level.

\section{Materials and Methods}

\section{Description of the study area}

The study was carried out in a slum area about seven (7) kilometers southwest of city centre and about five (5) kilometres southwest of industrial area. The village covers an area of about $3 \mathrm{~km}^{2}$, with a population density of approximately 40,881 people $\mathrm{km}^{-2}$ with a total of 42,722 households (CBS, 1989). Houses are constructed of mud, wood and roofed with corrugated iron sheets. The area is dotted with many cottage industries such as metal works, "Posho" milling, and timber works. There were a total of five sampling sites(A-E)(Fig 1) located on the small open spaces between the residential housing units. The area is crisscrossed with unpaved roads, a railway line, vehicle movements and burning of urban refuse in the open is a common phenomena. 


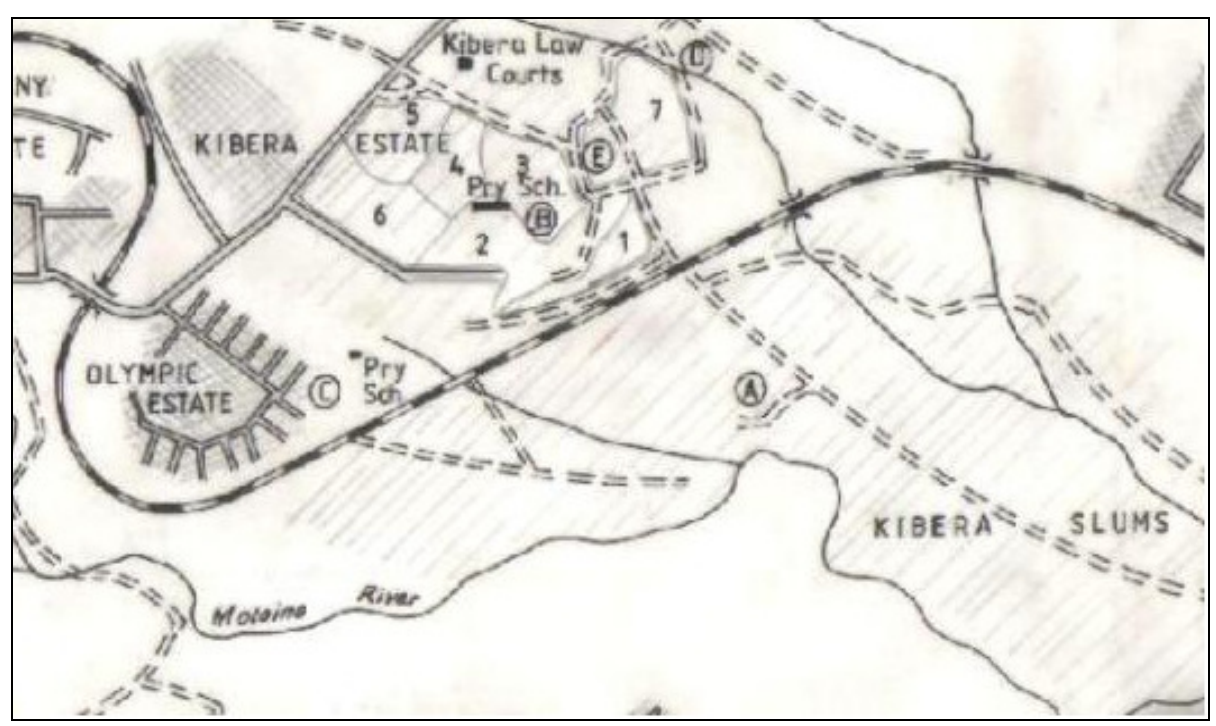

Figure 1: Map of the study area showing a section of the sub-urban part of Nairobi (A-E: represents the suspended particulate matter sampling points

\section{Sampling procedures}

Sampling was done using the "Gent" stacked filter unit (SFU)(Maenhaut et al; 1992; Thomas et al; 1994). The sampler is fitted with an impaction plate which produces a threshold of roughly $10 \mu \mathrm{m}$ for the size of incoming particles. The impaction plate was coated with vaseline oil to reduce particles bouncing off. The $\mathrm{PM}_{10}$ inlet was placed at a height of two metres above the ground for the first seven months and four metres for five months. Two polycarbonate nuclepore filters in sequence were used, both of $47 \mathrm{~mm}$ diameter. These were coarse $(8 \mu \mathrm{m}$ pore $)$ and fine $(0.4 \mu \mathrm{m}$ pore $)$ diameter to separate the coarse and fine fractions of the particulate matter respectively. The sampling was done over an eight hour period starting at between $8.00 \mathrm{AM}$ and ending at around 5.00 PM in the evening. A total of 126 duplicate coarse and fine particulate matter samples were collected in the five sites.

\section{Weighing of filters}

Filters were weighed in an air conditioned laboratory using $1 \mu \mathrm{g}$ sensitivity (Ainsworth Type 24N) weighing balance before and after sampling. Prior to weighing all filters were left to equilibriate for 24 hours in the room. They were irradiated with ${ }^{241} \mathrm{Am}$ $\alpha$-emitting source $(5 \mu \mathrm{Ci})$ to remove the static buildup before and after sampling (IAEA, 1996). All filter handling was done using plastic tweezers to avoid contamination by grease from fingers and by heavy metals from metallic tweezers.

\section{Spectral data analysis}

A Canberra S-100 PC based multichannel analyser (MCA) was used for spectral data acquisition and storage. Both the coarse and fine loaded filters were irradiated for 60,000 seconds using ${ }^{109} \mathrm{Cd}$ source. The analysis of the x-ray spectra was done by AXIL (Espen et al; 1985) and quantitative analysis of environmental samples (QAES) for spectral deconvolution and quantitative measurements (Kump, 1993).

\section{Sample analysis by AAS}

The loaded filters were digested by boiling gently in $20 \mathrm{ml}$ of high purity $70 \%$ nitric acid for 2 hours, cooled to room temperature and $10 \mathrm{ml}$ of $70 \%$ perchloric acid added. This solution was boiled gently for 30 minutes, cooled to room temperature and filled to $50 \mathrm{ml}$ mark in $1 \%$ nitric acid solution. Quantitative analysis was done by atomic absorption spectrometer, Model AA-680 (Shimadzu Corporation, 1991).

\section{Quality control}

The reliability of the analytical procedures was checked by analysis of standard reference materials (SRM-1648). Results of analysis by both Energy Dispersive X-ray Fluorescence (EDXRF) and Atomic Absorption 
Spectroscopy (AAS) showed good agreement with the certified values. Values obtained were within $10 \%$ range of the certified values. Selected fine and coarse particulate matter samples analysed by EDXRF were reanalysed by AAS, T-tests did not show any significance difference between the values obtained by the two techniques.

\section{Results and discussions \\ Coarse and fine particulate matter concentrations}

Coarse and fine particulate matter levels ( $\mu \mathrm{g}$ $\mathrm{m}^{-3}$ ) variation at two metres over the sampling period for the five sites are summarised graphically in Figures 2 and 3. The levels of coarse particulate matter recorded for each site reflected the location and kind of activities near the site. Site D nearest to unpaved road and several children's playground the highest mean monthly levels (123.6 to $233.9 \mu \mathrm{g} \mathrm{m}^{-3}$ ). Site E far away from any road/footpath, recorded low levels with most of the samples collected having a mean monthly values of less than $100 \mu \mathrm{g} \mathrm{m}^{-3}$. This is also noted for the fine suspended particulate matter samples. It should be noted that the ground cover around this site was mainly hence less soil dust. This points to dust blown off unpaved roads to be a major contributor to the load of suspended particulate matter in this area.

Site $\mathrm{C}$ located on an open field away from the slum houses recorded values comparable to site B.

The levels observed (23.1 to $152.2 \mu \mathrm{g}$ $\mathrm{m}^{-3}$ ) for this site could be due to several factors among them dust from unpaved roads/footpaths, vehicular emissions and burning refuse nearby.

For the fine particulate matter levels, sites A, B and $\mathrm{C}$ recorded comparable values for most of the months (Fig 3). Site D recorded the highest mean monthly levels (20.6 to $36.1 \mu \mathrm{g} \mathrm{m}^{-3}$ ) strongly suggesting the location and activities near the site were the main determinant of levels observed.

Trends similar to particulate matter loading obtained at two metres height was observed at four metres for both coarse and fine particulate matter samples (Figures 4 and 5). The highest value obtained at four metres was $184 \mu \mathrm{g} \mathrm{m}^{-3}$ at site $\mathrm{D}$ as compared to $233.9 \mu \mathrm{g} \mathrm{m}^{-3}$ at two metres height for coarse particulate matter samples.

For the fine particulate matter, sites B, C and D recorded values above $20 \mu \mathrm{g} \mathrm{m}^{-3}$ for most of the months but at four metres values below 20 $\mu \mathrm{g} \mathrm{m}^{-3}$ were observed. The maximum mean monthly value observed at four metres was 29 $\mu \mathrm{g} \mathrm{m}^{-3}$ observed at two metres. Reduction in particulate loading of between 17 to $45 \%$ was observed for the coarse particulate fraction while the fine particulate fraction registered reduction of between 18 to $40 \%$. Resuspended soil dust at the lower height was observed to contribute to the high levels of suspended particulate matter observed.

\section{Elemental concentrations}

The mean elemental concentration ranges $\left(\mu \mathrm{g} \mathrm{m} \mathrm{m}^{-3}\right)$ in the coarse and fine particulate matter fractions are given in Tables 1 and 2. The elements $\mathrm{K}, \mathrm{Ca}, \mathrm{Ti}, \mathrm{Mn}$ and $\mathrm{Fe}$ associated with crustal dust had the highest concentrations at both heights for both coarse and fine particulate matter fractions. Reduction in concentration of between 30 to $72 \%$ was observed in the coarse particulate fraction as compared to $25 \%$ for $\mathrm{Cu}, \mathrm{Zn}$ and $\mathrm{Br}$ at four metres height.

In the fine particulate matter fraction higher reductions of between 70 to $74 \%$ were observed for $\mathrm{Ca}$ and 26 to $61 \%$ for $\mathrm{Fe}$. However, slight reduction of between 10 to 23 \% were observed for $\mathrm{Ti}, \mathrm{Cu}, \mathrm{Zn}$ and $\mathrm{Pb}$. Elements $\mathrm{K}, \mathrm{Ca}, \mathrm{Ti}, \mathrm{Mn}$ and $\mathrm{Fe}$ represented 13.6 to $21.2 \%$ of the total coarse particulate mass at two metres and 10 to $18.2 \%$ at four metres height. A higher proportion (33.1 to $49.5 \%$ ) was observed for these elements in the fine particulate fraction at two metres than at four metres (11.2 to $17.3 \%)$. This could indicate the effect of resuspended soil dust is more pronounced in the fine particulate range. The elements $\mathrm{Cu}, \mathrm{Zn}, \mathrm{Pb}$ and $\mathrm{Br}$ associated with anthropogenic activities represented 0.5 to $1.1 \%$ of the total coarse particulate mass at both heights. Higher proportions were observed in the fine particulate fraction at both two metres (1.5 to $3.5 \%)$ and four metres (2.3 to $3.1 \%$ ) height. This could be attributed to the reduced levels of resuspended soil dust, and influence of incoming air masses, especially with the north easterlies prevalent in the area. 


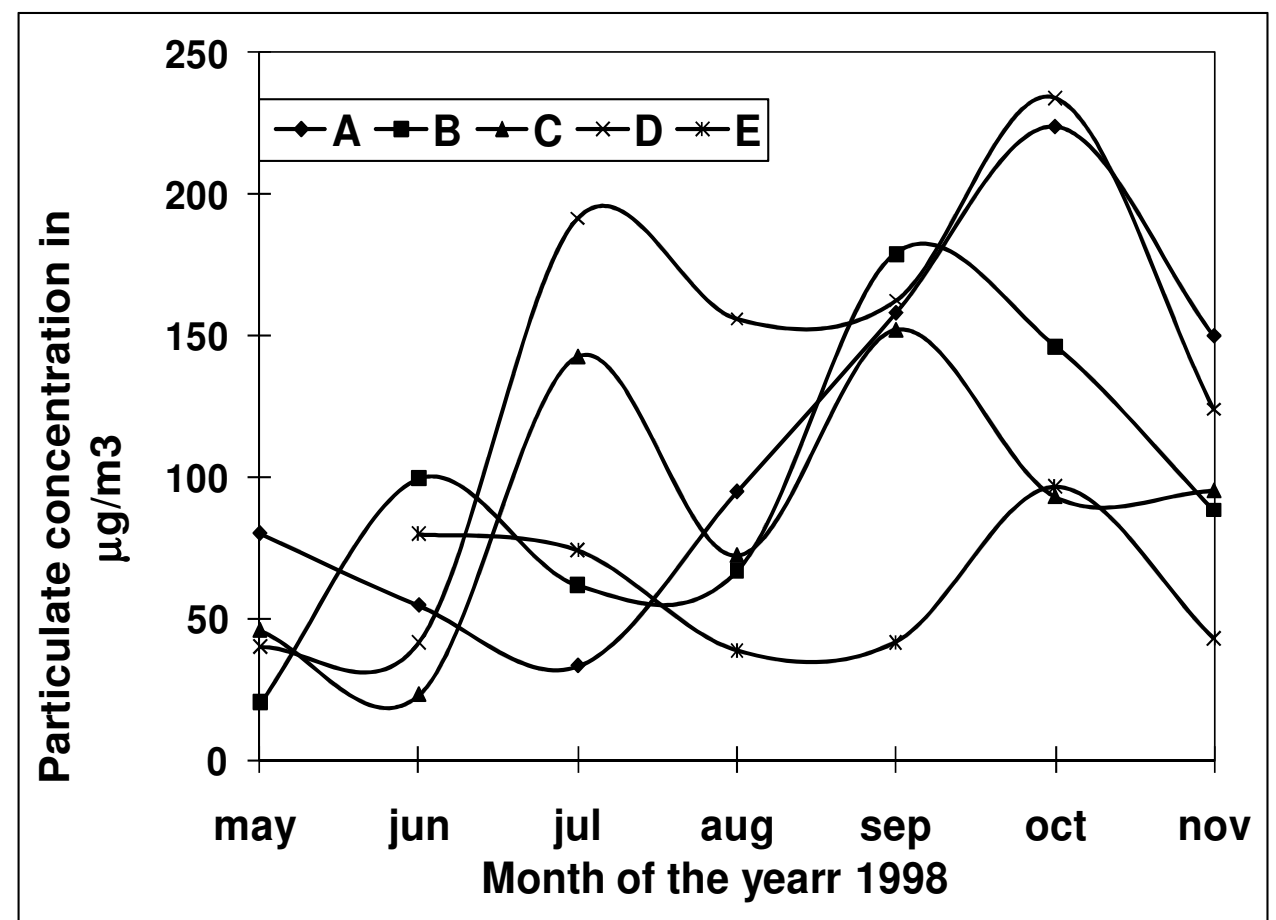

Figure 2: Variation of suspended coarse particulate matter levels with time for the various sampling sites at two meters height

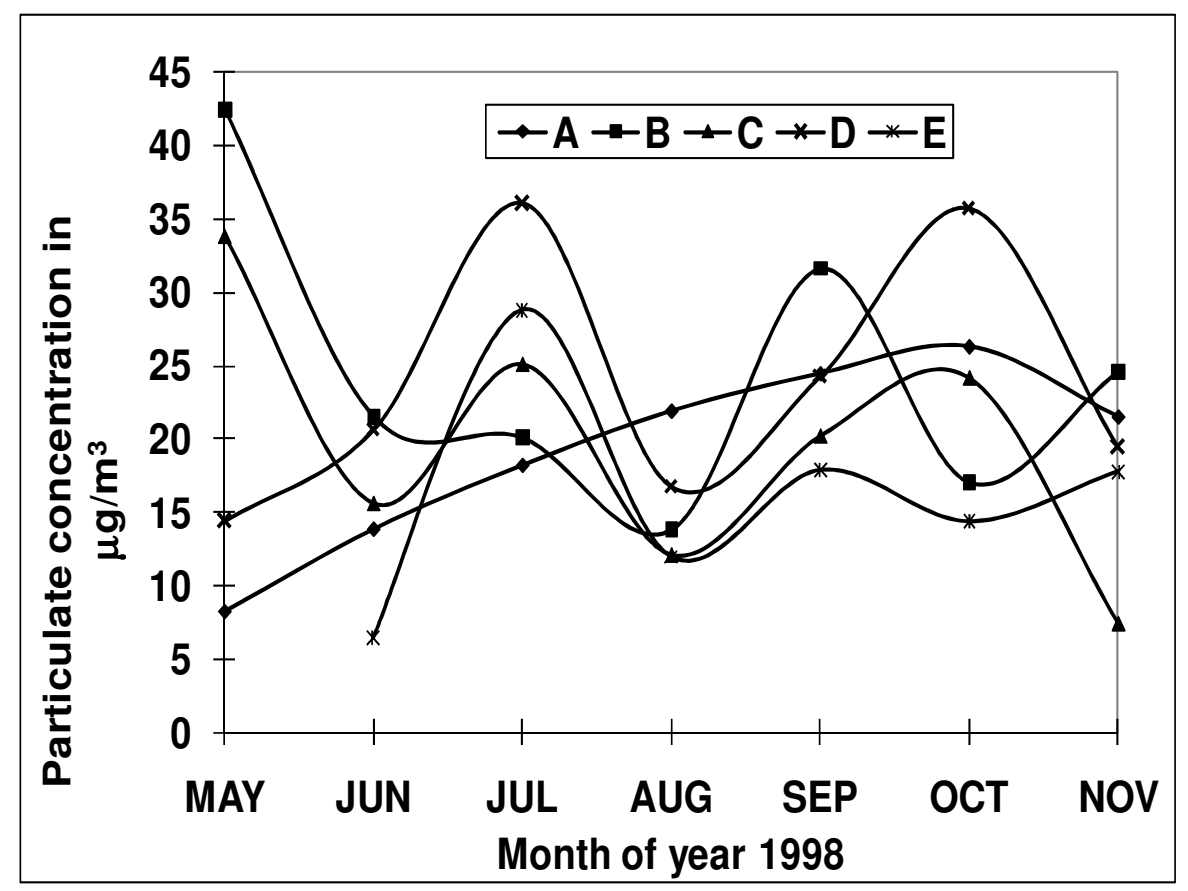

Figure 3: Variation of suspended fine particulate matter levels with time for the various sampling sites at two meters height 


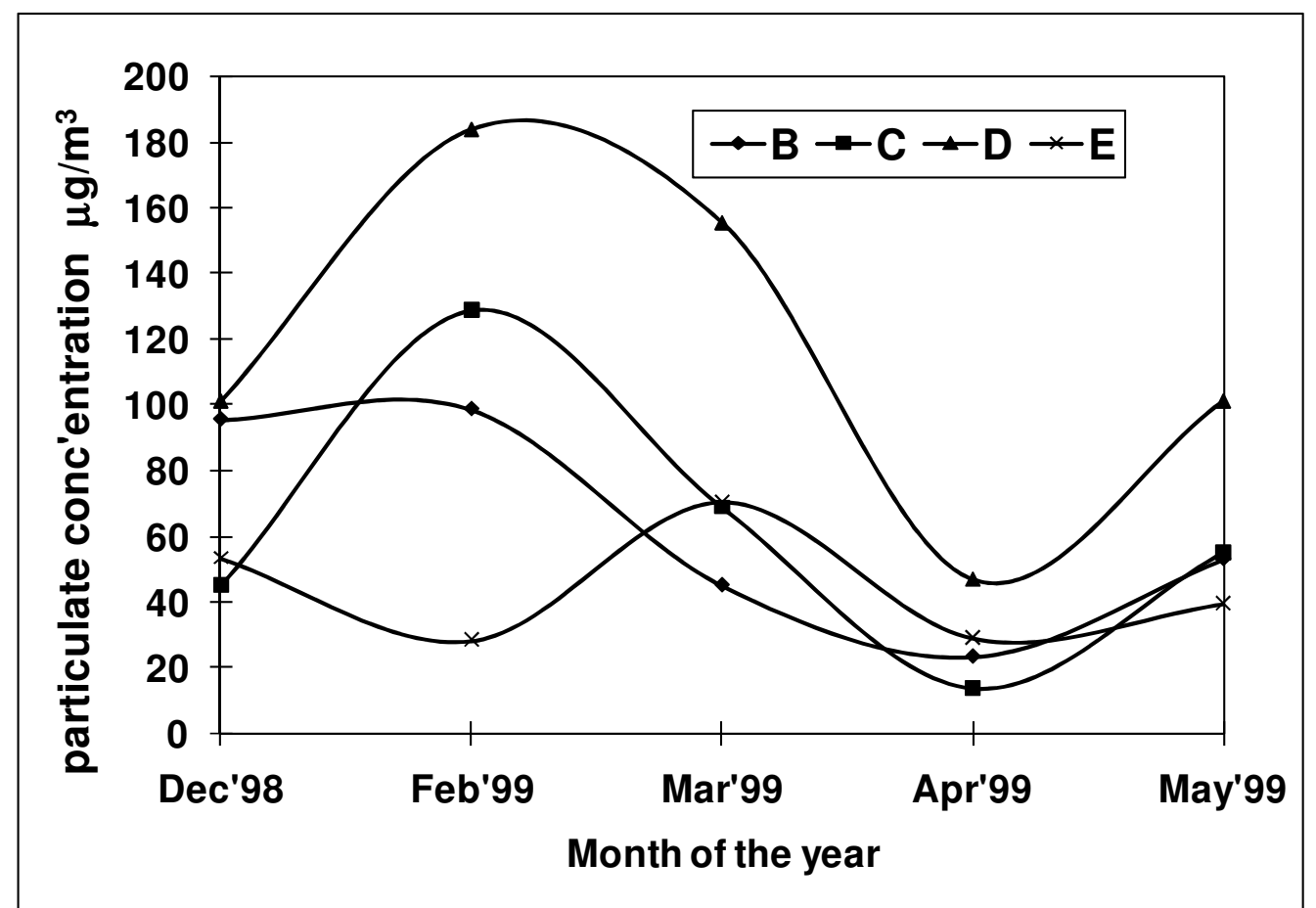

Figure 4: Variation of suspended course particulate matter levels with time for the various sampling sites at four meters height

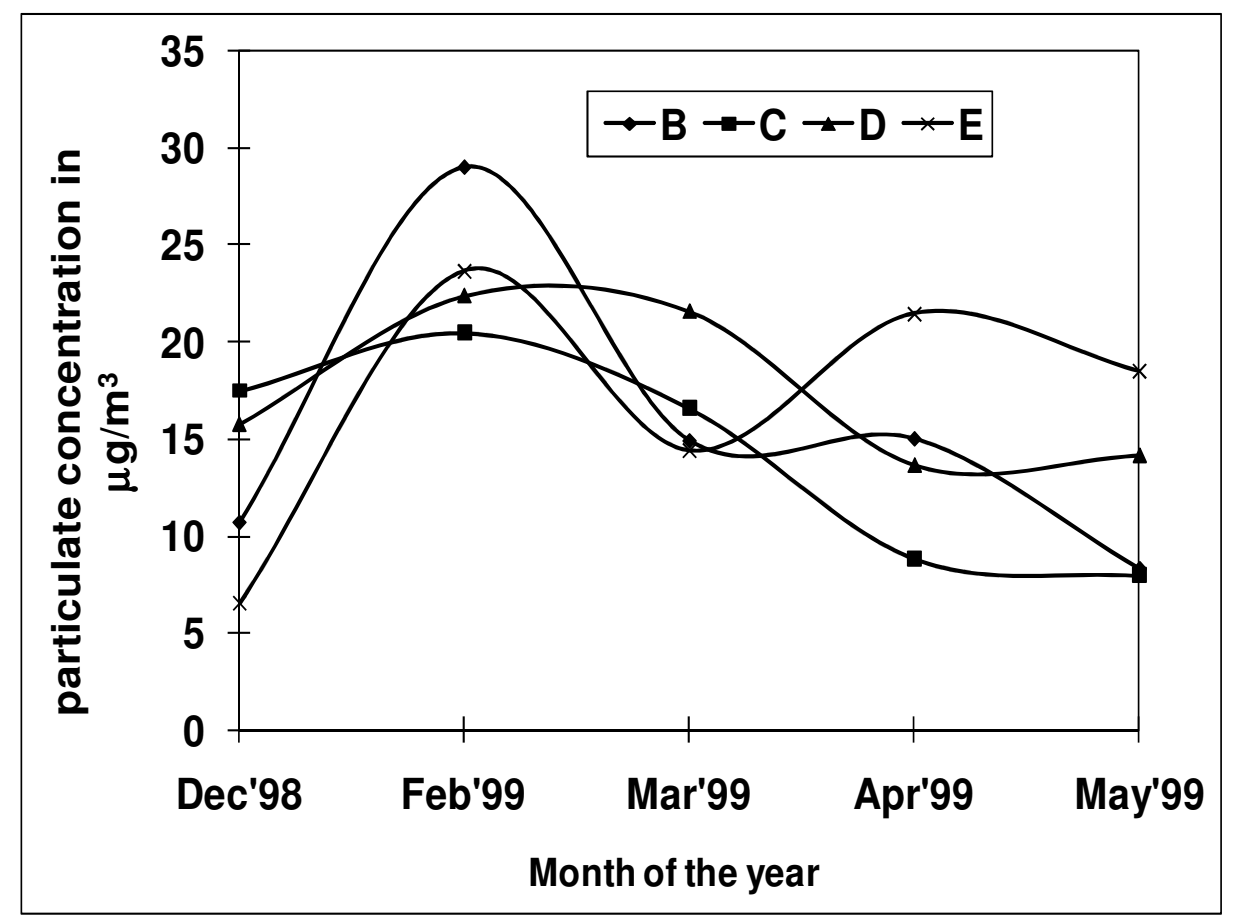

Figure 5: Variation of suspended fine particulate matter levels with time for the various sampling sites at four meters height 


\section{Correlation coefficients}

At two metres height

Correlations between the various crustal elements $\mathrm{K}, \mathrm{Ca}, \mathrm{Ti}, \mathrm{Mn}, \mathrm{Fe}, \mathrm{Zr}$ and SPM levels ranged between 0.612 to 0.984 in the coarse particulate matter fraction. The same elements correlate well (0.515 to 0.927$)$ with SPM levels in the fine particulate fraction for all the sites. However, high correlations (0.658 to 0.773 ) between $\mathrm{Zn}, \mathrm{Pb}$ and SPM were observed at site $\mathrm{D}$. This was attributed to probable surface dust contamination by fine particle fallout over time form metal works nearby and lead particles from vehicular emissions in near road. Pairwise correlations between the various crustal elements were $>$ 0.851 in the coarse particulate matter fraction, while in the fine particulate matter fraction they ranged from 0.552 to 0.942 . The correlations between $\mathrm{Zn}, \mathrm{Pb}, \mathrm{Cu}$ and $\mathrm{Br}$ were much weaker for most of the sites. However, strong correlations between $\mathrm{Pb}$ and $\mathrm{Br}(0.593$ to 0.971 ) were observed at sites $\mathrm{B}, \mathrm{C}$, and $\mathrm{E}$ in the fine particulate matter fraction.

\section{At four metres height}

A similar trend as obtained at two metres height is observed. Strong correlations between $\mathrm{Ca}, \mathrm{Ti}, \mathrm{Mn}, \mathrm{Fe}, \mathrm{Zr}$ and SPM ranging from 0.514 to 0.970 were observed for both coarse and fine particulate matter fractions for all the sites. However, an exception is $\mathrm{Cu}$ which shows high correlations (0.945 to 0.963 ) in the fine particulate matter fraction for all the sites. This could probably be attributed to transport from industrial area about seven kilometres away. The pairwise correlation coefficients between the various crustal elements $\mathrm{Ca}, \mathrm{Ti}, \mathrm{Mn}, \mathrm{Fe}$ and $\mathrm{Zr}$ ranged from 0.501 to 0.993 for both coarse and fine particulate matter fractions for all the sites. The correlations between the other elements are much weaker, except for $\mathrm{Br}, \mathrm{Pb}$ and $\mathrm{Cu}$ where the pairwise correlations ranged from 0.514 to 0.932 in the coarse particulate fraction in sites $\mathrm{B}, \mathrm{C}$ and $\mathrm{E}$.

\section{$\mathrm{Br} / \mathbf{P b}$ Ratios}

Site $\mathrm{D}$ had some of the highest $\mathrm{Br} / \mathrm{Pb}$ ratios ( 0.354 to 0.387 ) at both heights in both the coarse and fine particulate matter fractions. This could be due to the fact that this site was nearest to a busy road (Fig 1). At both heights higher $\mathrm{Br} / \mathrm{Pb}$ ratios were observed in the coarse particulate matter fraction. Higher $\mathrm{Br} / \mathrm{Pb}$ ratios were also observed at the lower height for both particulate matter fractions. This could be due to the vaporization of $\mathrm{Br}$ at the lower height (i.e, by the warm surface) hence more of the $\mathrm{Br}$ could be in the vapor phase at the higher height.

Automotive emissions are the most likely sources for $\mathrm{Br}$ and $\mathrm{Pb}$ as suggested by the good correlation between these two elements ( $r=0.593$ to 0.971$)$ at some of the sites and the average $\mathrm{Br} / \mathrm{Pb}$ ratios of $(0.339 \pm$ $0.023, \mathrm{n}=50$ ) for coarse particulate matter samples and $(0.307 \pm 0.035, \mathrm{n}=50)$ for the fine particulate matter samples at two metres height. These $\mathrm{Br} / \mathrm{Pb}$ ratios are similar to those observed in other sub-urban and urban areas in the world, 0.35 to 0.39 in cities and 0.25 in suburbs, 0.309 to 0.535 in a city (Karue et al; 1992; Gatebe et al; 1996).

\section{Enrichment factors \\ At two metres height}

Crustal enrichment factors (Efs) relative to Fe and Mason's average crustal rock composition (Mason, 1966) were calculated. In both the coarse and fine particulate matter fractions the Efs for elements $\mathrm{K}, \mathrm{Ca}, \mathrm{Ti}, \mathrm{Mn}$ and $\mathrm{Zr}$ were less than 6 (Table 3 and 4). These elements apart from $\mathrm{Zr}$ registered high concentrations in the coarse particulate matter fraction. However, $\mathrm{Mn}$ shows marginal enrichment (6.2 to 7.67) in the coarse particulate matter fraction and $\mathrm{Ca}$ (6.28 to 9.64) in the fine particulate matter fraction respectively. This points to probable local anthropogenic sources for these elements. These probably includes the frequent wood/charcoal/kerosine fires and burning of urban refuse. The other elements $\mathrm{Cu}, \mathrm{Zn}, \mathrm{Pb}$ and $\mathrm{Br}$ have high Efs values (12.4 to 1812) particularly in the fine particulate matter fraction and various anthropogenic sources are probably responsible for their atmospheric concentrations. $\mathrm{Cu}$ and $\mathrm{Zn}$ could mostly be attributed to local anthropogenic activities such as the metal welding works but dust transport from the industrial area about $3 \mathrm{kms}$ away by the prevalent north easterlies cannot be ruled out. $\mathrm{Pb}$ and $\mathrm{Br}$ are probably due to vehicular emissions.

\section{At four metres height}

A similar trend as observed for samples collected at two metres is evident. K, $\mathrm{Ca}, \mathrm{Ti}, \mathrm{Mn}$ and $\mathrm{Zr}$ showed low enrichment factors both in the coarse and fine particulate matter fractions. $\mathrm{Cu}, \mathrm{Zn}, \mathrm{Pb}$ and $\mathrm{Br}$ showed high enrichment factors. However marginal enrichment was observed for Mn (10.5 to 17) in the fine particulate matter fraction indicating possible anthropogenic sources. Higher enrichment factors were observed for $\mathrm{Cu}, \mathrm{Zn}$, $\mathrm{Pb}$ and $\mathrm{Br}$ at four metres height than at two 
metres in the fine particulate matter fraction. This could be due to the longer residence time of the fine particles in the air.

\section{Conclusion}

Similar suspended particulate matter (SPM) concentration profiles were observed at both heights for all the sites sampled. Site D recorded the highest levels while site $\mathrm{E}$ had the lowest at both heights. Reduction in particulate loading of between 17 to $45 \%$ was observed for the coarse particulate matter fraction while a reduction of between 18 to $40 \%$ were registered for the fine particulate matter faction.

Elements $\mathrm{K}, \mathrm{Ca}, \mathrm{Ti}, \mathrm{Mn}$ and $\mathrm{Fe}$ had the highest concentrations at both heights for both coarse and fine particulate matter fractions. Reduction in concentration of between 30 to $72 \%$ for $\mathrm{Ca}$, $\mathrm{Ti}$, and $\mathrm{Zr}$ was observed in the coarse particulate fraction, while $\mathrm{Cu}, \mathrm{Zn}$ and $\mathrm{Br}$ registered a reduction of $25 \%$ in the coarse particulate matter fraction. For the fine

\section{References}

Central Bureau of Statistics (CBS) (1989). Kenya Population Census, Pp1-3.

Espen Van P; Janssens, K; Sweenters, I (1995). AXIL-X-ray Analysis Software, Users Manual, Canberra Packard Industries, Benelex. Gatebe C.K; Kinyua, AM; Mangala, M.J; Kwach, R; Njau, LN; Mukolwe, E.A; Maina, DM (1996). Determination of suspended particulate matter of major significance to human health using Nuclear techniques in Kenya. Journal of Radioanalytical and Nuclear chemistry articles, vol 203, No1, pp125-134.

Gatebe C.K and Kinyua, AM (1994). Total suspended particulate matter in air of some urban areas in Kenya - A Review, International journal of Biochemiphysics $\mathrm{Vol}$ 3, No 1.

IAEA (1996) -International Atomic Energy Agency (IAEA-TECDOC)- operations guide on sampling and sample preparation procedures for XRF analysis of Environmental samples, pp 45-46.

Karue J.M; Kinyua, AM;. El Busaidy A.H.S (1992). Measured components in total suspended particulate matter in a Kenyan urban area. Atmospheric Environment,

26B, pp505.

Khandekar R. N; Kelkar, DN; and Vohra, KG (1980). Lead, cadmium, zinc, copper and iron in the atmosphere of greater Bombay. Atmospheric Environment, Vol. 14, pp 457461. particulate fraction higher reductions of between 70 to $74 \%$ were observed for $\mathrm{Ca}$ and 26 to $61 \%$ for $\mathrm{Fe}$. Elements $\mathrm{Cu}, \mathrm{Zn}, \mathrm{Pb}$ and $\mathrm{Br}$ associated with anthropogenic activities represented 0.5 to $1.1 \%$ of the total coarse particulate mass at both heights. Higher proportions were observed in the fine particulate matter fraction at both two and four metres height. At both heights higher $\mathrm{Br} / \mathrm{Pb}$ ratios were observed in the coarse particulate matter fraction. Higher $\mathrm{Br} / \mathrm{Pb}$ ratios were also observed at the lower height for both particulate matter fractions.

Automotive emissions are the most likely sources of $\mathrm{Br}$ and $\mathrm{Pb}$ as indicated by the good correlation $(\mathrm{r}>0.593)$ observed at some sites and the $\mathrm{Br} / \mathrm{Pb}$ ratios $(0.339 \pm 0.023)$ for coarse particulate matter and $(0.307 \pm 0.035)$ for fine particulate matter samples. $\mathrm{Cu}$ and $\mathrm{Zn}$ were probably from anthropogenic activities within and outside the area.

Kump P. (1993). Quantitative Analysis of Environmental Samples (QAES). Private communication

Maenhaunt W; Filip, F and Jan C. (1992). Institute for nuclear sciences, University of Gent, Belgium. The "Gent" Stack Filter Unit (SFU) sampler for the collection of atmospheric aerosols in two size fractions. Description and instructions for installation and use. IAEA Co-ordinated Research programme, CRP E4-10.08.

Mahadevan T. N; Negi, BS and Meenasky, V (1989). Measurement of elemental composition of aerosol matter and precipitation from a remote background site in India. Atmospheric Environment, Vol 23, No 4, pp 869-874.

Mason B. (1966). Principles of geochemistry, $3^{\text {rd }}$ Edition. Wiley, Newyork, pp 46-47.

Nguyen, TH. (1997). Trace element analysis with application to environmental pollutant studies in Vietnam. PHD Thesis. Environmental Physics Group, Physics and Engineering physics, Chalmers University of Technology and Goteborg University, S-41296 Goteborg Sweden.

Noll K. E; Yuen P and Feng Y. P (1990). Atmospheric coarse particulate concentrations and dry deposition fluxes for ten metals in two urban environments. Atmospheric Environments, Vol 24A, pp 903 - 908. 
Prasad A. S (1988). In current Topics in Nutrition and Disease Volume 18: Essential and Toxic trace elements in Human Health and Disease. Alan R. Liss. Inc, Newyork

Shimadzu Corporation (Japan) (1991), Instruction Manual, AA-680 Atomic Absorption/Flame Emission Spectrometer.
Thomas, A C; Robert, A E; Patrick, J F; Peter, J.B and Wilkinson, LK. (1994). The stacked filter unit revisited. Air quality group, Crocker, Nuclear laboratory. University of California, Davis C. A. 95616.

\section{Acknowledgements}

This work could not have been possible without the cooperation of the owners of the five houses in the study area who provided electricity outlet to power the sampling pump and the Institute of Nuclear Science (University of Nairobi) for providing funds and the EDXRF instrument for analysis of the samples.

Table 1: Mean elemental concentration $\left(\mu \mathrm{g} \mathrm{m}^{-3}\right)$ range at heights of two and four metres for the suspended coarse particulate matter samples

\begin{tabular}{|l|l|l|}
\hline Element & Two (2) metres & Four (4) metres \\
\hline $\mathrm{K}$ & $1.435-4.533(1.804)$ & ------- \\
\hline $\mathrm{Ca}$ & $5.185-7.104(7.054)$ & $1.55-1.97 \quad(1.745)$ \\
\hline $\mathrm{Ti}$ & $0.387-0.809(0.419)$ & $0.233-0.541(0.447)$ \\
\hline $\mathrm{Mn}$ & $0.381-0.790(0.526)$ & $0.277-0.656(0.455)$ \\
\hline $\mathrm{Fe}$ & $3.485-6.025(5.148)$ & $2.31-6.29(4.125)$ \\
\hline $\mathrm{Cu}$ & $0.119-0.169(0.135)$ & $0.095-0.117(0.102)$ \\
\hline $\mathrm{Zn}$ & $0.143-0.247(0.195)$ & $0.118-0.165(0.157)$ \\
\hline $\mathrm{Pb}$ & $0.168-0.337(0.243)$ & $0.120-0.222(0.156)$ \\
\hline $\mathrm{Br}$ & $0.029-0.064(0.059)$ & $0.045-0.054(0.049)$ \\
\hline $\mathrm{Zr}$ & $0.046-0.152(0.096)$ & $0.036-0.095(0.071)$ \\
\hline
\end{tabular}

(Median value shown in parenthesis) $* \mathrm{~K}$ at four metres could not be used for intercomparison because it was only detected in two of the five months sampled at only two of the four sites.

Table 2: Mean elemental concentration $(\mu \mathrm{g} \mathrm{m-3})$ range at heights of two and four metres for the suspended fine particulate matter samples

\begin{tabular}{|l|l|l|}
\hline Element & Two (2) metres & Four (4) metres \\
\hline $\mathrm{K}$ & $1.503-2.25(1.78)$ & LDL \\
\hline $\mathrm{Ca}$ & $4.77-6.298(5.481)$ & $1.45-1.65 \quad(1.550)$ \\
\hline $\mathrm{Ti}$ & $0.133-0.280(0.238)$ & $0.222-0.245(0.234)$ \\
\hline $\mathrm{Mn}$ & $0.079-0.110(0.095)$ & $0.107-0.192(0.123)$ \\
\hline $\mathrm{Fe}$ & $0.862-1.102(0.982)$ & $0.326-0.818(0.518)$ \\
\hline $\mathrm{Cu}$ & $0.075-0.135(0.088)$ & $0.088-0.115(0.099)$ \\
\hline $\mathrm{Zn}$ & $0.106-0.150(0.132)$ & $0.081-0.116(0.110)$ \\
\hline $\mathrm{Pb}$ & $0.165-0.250(0.233)$ & $0.162-0.225(0.187)$ \\
\hline $\mathrm{Br}$ & $0.031-0.055(0.052)$ & $0.031-0.034(0.033)$ \\
\hline $\mathrm{Zr}$ & $0.011-0.027(0.016)$ & $0.012-0.022(0.016)$ \\
\hline
\end{tabular}

(Median value shown in parenthesis)(LDL-low detection limits) 